\title{
Signal of a Serious Risk
}

National Cancer Institute

\section{Source}

National Cancer Institute. Signal of a Serious Risk. NCI Thesaurus. Code C142688.

Information related to a serious adverse drug experience associated with use of a drug and derived from-(a) a clinical trial; (b) adverse event reports; (c) a post-approval study;

(d) peer-reviewed biomedical literature; (e) data derived from the post-market REMs.

[505-1(b) of FD\&C Act (21 USC. 355-1(b)] 